\title{
Solid-State Lighting
}

\author{
Colin J. Humphreys (Cambridge University, UK)
}

\begin{abstract}
Electricity generation is the main source of energy-related greenhouse gas emissions and lighting uses one-fifth of its output. Solid-state lighting using light-emitting diodes (LEDs) is poised to reduce this value by at least $50 \%$, so that lighting will then use less than one-tenth of all electricity generated. LED lighting will provide reductions of at least $10 \%$ in fuel consumption and carbon dioxide emissions from power stations within the next 5-10 years. Even greater reductions are likely on a 10-20-year timescale.
\end{abstract}

\section{Electrical Appliances, Lighting, and Energy}

At first sight, a 100-W incandescent light bulb might not seem to be a key target for energy savings. An electric oven can consume much more electricity, up to $5,000 \mathrm{~W}$, as can an electric clothes dryer. A window-unit air conditioner uses typically $1000 \mathrm{~W}$; a four-slot toaster, $1500 \mathrm{~W}$; a desktop computer plus monitor, $200 \mathrm{~W}$; and a 19-in. (48-cm) television, $70 \mathrm{~W}$. However, the average house in the United States has 45 light bulbs; in Canada, 30; and in the United Kingdom, 25. Considering a house with 30 light bulbs rated at $100 \mathrm{~W}$ and assuming that the bulbs are all of the incandescent type (a heated tungsten wire in a vacuum bulb), then $3,000 \mathrm{~W}$ is used to light the house. In addition, the average light bulb is switched on for $4 \mathrm{~h}$ per day, so lighting a house consumes about 12 kilowatt-hours (kWh) of electricity per day. By comparison, an electric toaster is likely to be switched on for only a few minutes each day, so it consumes only about $0.1 \mathrm{kWh}$ per day. Taking all buildings together (residential, industrial, and commercial), lighting is the second largest user of energy in buildings. ${ }^{1}$

Not only does lighting consume a significant amount of energy, it is also extremely inefficient. Incandescent light bulbs convert about $5 \%$ of the electricity they use into visible light. Even energy-saving compact fluorescent lamps (a phosphorcoated gas discharge tube) are only about $20 \%$ efficient. These low efficiencies contrast starkly with the efficiencies of most of the household appliances just mentioned. For example, electric ovens, clothes dryers, and toasters convert electricity to useful heat with a typical efficiency of at least $70 \%$. Electric motors for fans are typically $90 \%$ efficient. There is therefore much more potential for large energy savings from lighting than from most other appliances. Indeed, lighting is so inefficient, and it consumes so much energy, that there is probably more potential for large energy savings in this field than in any other area.

\section{Lighting, Energy, and Carbon Dioxide Emissions}

The total annual energy consumption in the United States was about 9,200 terawatt-hours (TWh) in 2001 (one terawatt is one million million watts). ${ }^{2}$ Thirty-eight percent of that energy was consumed as electricity, and of that, $22 \%$, or $765 \mathrm{TWh}$, was consumed by lighting. ${ }^{2}$ Thus, over $8 \%$ of total energy consumption in the United States was for lighting: this is a significant fraction. At $\$ 0.068 / \mathrm{kWh}$, the average cost of electricity in the United States in 2001, the electricity cost to end users was about $\$ 53$ billion. $^{2}$ (It should be noted that the cost of electricity has risen significantly since 2001 . The average cost of residential electricity in March 2006 was $\$ 0.099 / \mathrm{kWh}$ in the United States and $\$ 0.2 / \mathrm{kWh}$ in the United Kingdom).

Worldwide, grid-based electric lighting consumed about $2,650 \mathrm{TWh}$ of electricity in 2005 , some $19 \%$ of total global electricity consumption. ${ }^{3}$ The energy bill for electric lighting cost end users $\$ 234$ billion and accounted for two-thirds of the total cost of the electric-lighting service ( $\$ 356$ billion), which includes lighting equipment and labor costs as well as energy. ${ }^{3}$ An average cost of \$2.8 per megalumen-hour (Mlmh) was used by the International Energy Agency in producing those values. ${ }^{3}$ The annual cost of grid-based electric lighting is about $1 \%$ of global gross domestic product (GDP).

It is not widely realized that lighting is one of the biggest causes of greenhouse gas emissions. The energy consumed to supply lighting throughout the world entails greenhouse gas emissions of 1900 megatonnes (Mt) of $\mathrm{CO}_{2}$ per year (assuming an energy mix based on the 2005 world electricity generation values of $40 \%$ from coal, $20 \%$ from natural gas, $16 \%$ from hydropower, $15 \%$ from nuclear, $7 \%$ from oil, and $2 \%$ from renewables other than hydro). ${ }^{4}$ This is equivalent to $70 \%$ of the emissions from the world's cars and over three times the emissions from aircraft. ${ }^{3}$ In addition, many developing countries do not have grid-based electricity and produce lighting using oil lamps. This is responsible for only $1 \%$ of global lighting, but is hugely inefficient and accounts for $20 \%$ of lighting $\mathrm{CO}_{2}$ emissions. The oil consumed for oil-lamp lighting is $3 \%$ of the world's oil supply, more than the total output of Kuwait. ${ }^{3}$

Worldwide demand for lighting is increasing rapidly. The average North American consumes over $100 \mathrm{Mlmh}$ each year of 
lighting, whereas the average person in India uses only $3 \mathrm{Mlmh}$. In addition, the world population is increasing rapidly, from 5 billion in 1987 to 6.7 billion today, an increase of $34 \%$ in the past 20 years. A conservative estimate is that the global demand for artificial lighting will be $80 \%$ higher by $2030 .{ }^{3}$ I believe that this estimate severely underestimates the fact that the average person in India will not be content with having less than $3 \%$ of the lighting of the average person in the United States. My estimate is that global demand for lighting might be three times higher by 2030. If this turns out to be correct, and if we do not move to more efficient lighting, then by 2030 , lighting will be responsible for emitting more than twice the $\mathrm{CO}_{2}$ of all of today's cars and nine times the emissions of all of today's aircraft.

\section{Lighting and the Human Eye}

The human eye is sensitive only to light in the visible spectrum, ranging from violet (with a wavelength of about $400 \mathrm{~nm}$ ) through red (with a wavelength of about $700 \mathrm{~nm}$ ). The maximum sensitivity of the human eye is to green light with a wavelength of $555 \mathrm{~nm}$. The lumen is the unit of light intensity perceived by the human eye. What is called the efficacy of a light source takes into account the sensitivity of human vision, so that green light contributes more strongly to efficacy than blue or red light and ultraviolet and infrared wavelengths do not contribute at all. The units of efficacy are lumens per watt $(\mathrm{lm} /$ $\mathrm{W}$ ), corresponding to light power out (as perceived by the human eye and measured in lumens) relative to electrical power in (measured in watts). It is important to note that efficacy is different from efficiency. The efficiency of a light source is the light power out, not adjusted for the response of the human eye, divided by the electrical power in. Efficiency is dimensionless and is usually given as a percentage. The terms efficiency and efficacy are both widely used in lighting, and care must be taken not to confuse them.

The maximum possible efficacy of a light source is $683 \mathrm{~lm} /$ $\mathrm{W}$, for the case of monochromatic 555-nm green light. The maximum possible efficacy for an ideal white light source is $240 \mathrm{~lm} / \mathrm{W}$ (because the human eye is less sensitive to wavelengths on each side of green). Such an ideal source reproduces colors perfectly and has a color rendering index (CRI) of 100 . The CRI is an internationally accepted measure of how well a light source renders colors. The CRI varies between 0 and 100, with 100 representing perfect color rendering. A CRI of $90 \%$ is considered to be excellent, and the maximum possible efficacy of a white light source with a CRI of $90 \%$ is $4081 \mathrm{~m} / \mathrm{W}$. It is useful to bear this value in mind when reading this article, as it represents a theoretical maximum efficacy for excellent quality white lighting.

\section{The Range of Lighting Options Incandescent Light Bulbs}

It is commonly believed that Thomas Edison invented the incandescent light bulb in 1879. This is not correct. In 1860, the English scientist Joseph Swan obtained a U.K. patent for a carbon-filament incandescent lamp operating in a partial vacuum. Swan received another U.K. patent in 1878 for a carbonfilament incandescent lamp operating in an improved vacuum. In the United States, Edison had been working on copies of the original 1860 patent of Swan. He founded the Edison Electric Light Company in 1878 and patented a more efficient version of Swan's invention in 1879. Swan sued Edison for patent infringement and won. In 1881, Swan started his own company, the Swan Electric Light Company, and began commercial production of incandescent light bulbs. In 1883, Edison and Swan joined forces, and the Edison and Swan United Electric Light Company was established, commonly known as Ediswan. The company sold the lamps that Swan had developed in 1881. So Swan invented the light bulb, but Edison was better at popularizing and developing it.

It is difficult to think of many other inventions that we still use today, essentially in their original form, that are over 100 years old. An incandescent light bulb uses electricity to heat a coiled tungsten wire in an evacuated glass bulb. The temperature of the wire is about $3,500 \mathrm{~K}$ and it glows white-hot, radiating white light. The lifetime of an incandescent light bulb is typically $1000 \mathrm{~h}$.

The spectrum of radiation emitted is very broad. It fills the entire wavelength range $(400-700 \mathrm{~nm})$ of the human eye. Because its visible spectrum is so broad, it renders colors extremely well. An incandescent light bulb has a CRI approaching 100. However, it also emits strongly in the infrared as heat, beyond the response of the human eye. Only about $5 \%$ of the input electrical energy is converted to visible light, and the rest is emitted as heat, so the incandescent light bulb is $95 \%$ inefficient at producing light. The efficacy of an incandescent light bulb is typically $15 \mathrm{~lm} / \mathrm{W}$.

\section{Fluorescent Tubes}

The first fluorescent tube was made by General Electric (GE) in 1937. Fluorescent tubes consist of a glass tube filled with an inert gas, usually argon, and small amounts of mercury, typically $3-15 \mathrm{mg}$. Ultraviolet (UV) light is created by passing an electric current between electrodes at each end of the tube, which excites electrons in the mercury vapor. When the excited electrons relax, UV light is emitted. The UV light excites phosphors coating the inner surface of the glass tube, and these emit visible light.

Fluorescent tubes have much longer lifetimes $(7,500$ $30,000 \mathrm{~h}$ ) than incandescent light bulbs $(1000 \mathrm{~h})$. The quality of white light emitted depends on the phosphors used, but a warmwhite fluorescent tube has phosphors emitting in the blue, green, and red ranges. The efficacy of a fluorescent tube (60$100 \mathrm{~lm} / \mathrm{W}$ ) is much higher than that of an incandescent light bulb $(15 \mathrm{~lm} / \mathrm{W})$, and the efficiency is typically $25 \%$, compared to $5 \%$ for an incandescent bulb. These advantages, combined with reasonable costs, led to fluorescent tubes rapidly replacing incandescent lighting in the workplace, especially in offices and public buildings. Today, fluorescent tubes dominate lighting in the workplace.

\section{Compact Fluorescent Lamps}

Compact fluorescent lamps (CFLs) were first commercialized in the early 1980s. They usually consist of two, four, or six small fluorescent tubes, which can be straight or coiled. Their efficacy is typically $35-80 \mathrm{~lm} / \mathrm{W}$, and their efficiency is typically $20 \%$. CFLs usually have a lifetime of between 6,000 and $15,000 \mathrm{~h}$; however, this long lifetime is attained only if the lamp is left on for long periods of time. The lifespan of a CFL is significantly shorter if turned on for only a few minutes at a time: in the case of a 5-min on/off cycle the lifespan of a CFL has been measured to be only about $1000 \mathrm{~h}$, the same as that of an incandescent bulb. ${ }^{5}$ Hence, the lifetime of a CFL is a sensitive function of how it is used.

\section{Inorganic LEDs}

Inorganic materials emitting red light were first demonstrated by Holonyak and Bevacqua in 1962. ${ }^{6}$ Subsequent developments led to a range of colored light sources known as light-emitting diodes (LEDs). In particular, the first bright blue LED was announced by Nakamura at a press conference on November 12 , 1993. ${ }^{7}$ If a blue gallium nitride $(\mathrm{GaN})$ based LED is coated with a phosphor, then white light can be produced (in much the same 
way as UV-emitting fluorescent tubes and compact fluorescent lamps coated with a phosphor produce white light). Such white LEDs can last up to $100,000 \mathrm{~h}$, and unlike with CFLs, this lifetime is not reduced if the periods of use are short. The best white LEDs have an efficiency of $30 \%$ and an efficacy of $100 \mathrm{~lm} / \mathrm{W}$. Over $\$ 4$ billion worth of GaN-based LEDs were sold in $2006 .{ }^{7}$ Sales of high-brightness (HB) LEDs have had a compound annual growth rate of over $46 \%$ since $1995 .^{8,9}$

\section{Organic LEDs}

Organic LEDs are known as OLEDs (inorganic LEDs are simply called LEDs). Light-emitting organic materials were first demonstrated by Pope, Kallmann, and Magnante in 1963, ${ }^{10}$ within one year of the demonstration in 1962 of light emission from inorganic materials. Subsequent development led to a range of colored OLEDs based on polymeric or molecular thin films. In theory, OLEDs have a number of attractive properties for solid-state lighting, including ease of processing and low cost, as well as the ability for device properties to be tuned by chemically modifying the molecular structure of the organic thin films. ${ }^{11}$ However, despite some impressive research results, in practice, the development of OLEDs for lighting has lagged behind that of LEDs. So far, it has not been possible to achieve simultaneously high brightness at high efficiency with long lifetime. For this reason, unlike for white LEDs, no white OLEDs for lighting are commercially available. ${ }^{8}$

\section{The Coming Era of the Compact Fluorescent Lamp}

In the world of lighting, the past 130 years have been the age of the incandescent light bulb. However, we are now poised for a major sea change: the next five years or so will be the era of the CFL. What is precipitating this change is the realization by governments around the world of the huge $95 \%$ inefficiency of incandescent light bulbs and the fact that banning the sales of these bulbs is therefore one of the easiest and most effective ways of saving energy and reducing carbon dioxide emissions. For example, on September 27, 2007, the U.K. government announced that shops would stop selling $150-\mathrm{W}$ filament light bulbs by January 2008, 100-W bulbs by January 2009, 60-W bulbs by January 2010, and 40-W bulbs by December 2011 . What form of lighting is available now to take over from incandescent light bulbs? Long fluorescent tubes have already largely taken over in offices, commercial buildings, and factories, and any remaining incandescent bulbs in these buildings are likely to be replaced rapidly by such tubes. Concerning lighting in houses, although white inorganic LEDs are commercially available and widely used in various lighting applications, they are currently too expensive for general household lighting. White OLEDs are not commercially available for lighting. ${ }^{8}$ We therefore have one, and only one, realistic replacement for incandescent bulbs in homes at the present time: compact fluorescent lamps. These lamps have both advantages and disadvantages.

The main advantage of CFLs over incandescent bulbs is efficiency. CFLs are about four times as efficient as traditional incandescent bulbs. Martin Goetzeler, the CEO of Osram, has stated that shifting just $30 \%$ of the world's lighting to CFLs will cut global carbon dioxide emissions by $270 \mathrm{Mt}$ and save 460 billion kWh of electricity. ${ }^{12}$ These are substantial savings. The next major advantage of CFLs is lifetime: CFLs typically have a lifetime of about $10,000 \mathrm{~h},{ }^{3}$ compared to $1000 \mathrm{~h}$ for incandescent bulbs. However, if a CFL is left on for only short periods of time, its lifetime can drop to $1000 \mathrm{~h}$ or less.

The first generation of CFLs had many drawbacks. They were expensive, costing about $\$ 15$ each; the light they emitted was cold and harsh; they came on slowly, taking up to 2 min to reach full brightness; they could not be dimmed; and their brightness decreased over time and also dropped dramatically if the temperature became too low or too high. This latter point meant that they could not be used to illuminate refrigerated displays in supermarkets, for example, or in situations where the temperature might become too hot.

However, recently, CFLs have significantly improved. The cost of a CFL today can be less than $\$ 4$ (depending on the style), and the cost is continuing to fall. The color rendering of CFLs has improved considerably, and warmer white light is now available, with a CRI of up to 90. CFLs with electric ballast (the earlier generation had magnetic ballast, which was primarily responsible for the flickering and slow starting traditionally associated with fluorescent lighting, and buyers should beware that these are still widely available) turn on much more rapidly and can also be dimmed. However, switching on a CFL for short periods of time will still shorten its lifetime, and CFLs still lose a lot of brightness in cold or hot temperatures.

Returning to the increased efficiency of a CFL, each $13-\mathrm{W}$ CFL, over its expected 10,000-h life (given the right operating conditions) will save $470 \mathrm{kWh}$ of electricity compared to its equivalent $60-\mathrm{W}$ incandescent bulb. This results in reduced emissions of over $730 \mathrm{lb}(330 \mathrm{~kg})$ of carbon dioxide, as well as reductions of $1.6 \mathrm{lb}(0.73 \mathrm{~kg})$ of nitrogen oxides and $4.3 \mathrm{lb}$ $(2.0 \mathrm{~kg})$ of sulfur dioxide. Each incandescent bulb replaced by a CFL will save the householder, over the 10,000-h assumed lifetime of the CFL, about $\$ 50$ in the United States and about $\$ 100$ in the United Kingdom (assuming typical 2007 household electricity costs of $\$ 0.1 / \mathrm{kWh}$ in the United States and $\$ 0.2 / \mathrm{kWh}$ in the United Kingdom). For these reasons, sales of CFLs are soaring. Walmart, for example, plans to sell 100 million CFLs in 2007 .

However, CFLs have an environmental drawback. Each CFL contains about $5 \mathrm{mg}$ of mercury, which is a highly toxic cumulative heavy metal poison. There are 23 million houses in the United Kingdom, with 25 light bulbs per house on average. If all of these light bulbs are replaced by CFLs, there will be over 2 million grams (i.e., $2 \mathrm{t}$ ) of mercury in CFLs in U.K. houses. Neither the CFLs nor the boxes in which they are sold state that the contents contain mercury, and the U.K. government is providing no special disposal facilities. Hence, when CFLs fail, householders will throw them into their normal trash can; the garbage truck will collect the waste and compact it, breaking the CFL; and the mercury will spill out and contaminate the refuse, which will then enter incinerators and landfill sites. From incinerators, the mercury will enter the atmosphere, and from landfill sites, it can leech out into water supplies and into vegetables subsequently grown on the land.

There are 130 million houses in the United States, each containing 45 light bulbs on average. If these are replaced by CFLs, then there will be over 29 million grams (i.e., 29 t or 32 tons) of mercury in CFLs in U.S. houses. The potential for serious mercury contamination is therefore significant. By comparison, a mercury thermometer contains $500 \mathrm{mg}$ of mercury. If we assume that each house in the United States has one mercury thermometer, then there are 65 million grams ( $65 t$ or 72 tons) of mercury in thermometers in houses in the United States. This value is comparable to the amount of mercury in CFLs; however, the chances of breaking a CFL, and releasing the mercury, are probably far higher than those of breaking a thermometer. At least 10 U.S. states have banned the sale of mercury thermometers, as have many countries worldwide, yet such thermometers appear to be safer than CFLs.

Mercury can exist in coal and other fossil fuels. When these fuels burn, mercury vapor is released into the atmosphere where 
it is spread widely by air currents. Coal-fired power plants in the United States emit about 48 tons ( $43 \mathrm{t}$, or 43 million grams) of mercury annually. ${ }^{13}$ About $20 \mathrm{mg}$ of mercury is emitted to produce the electricity needed to run an incandescent light bulb for a period equivalent to the assumed 10,000-h lifetime of a low-energy CFL. Because this is greater than the $5 \mathrm{mg}$ of mercury contained in a CFL, it can therefore be argued that using a CFL produces a net saving of mercury. However, if carbon dioxide emissions from power plants can be captured, then it would make sense to capture the mercury emissions as well. In addition, whereas the mercury emitted from coal-fired power stations is spread over a large area, the mercury from broken CFLs will be concentrated in homes, incinerators, and landfill sites, where it is much more of a hazard than the widespread but very thin layer of mercury contamination from coal-fired power plants.

Mercury levels in many countries are already dangerously high. For example, a survey conducted by the U.S. Center for Disease and Prevention and published in 2003 found that, in the United States, one in $12(8 \%)$ U.S. women of child-bearing age had mercury in their blood above the levels considered safe by the Environmental Protection Agency. ${ }^{13}$ It is therefore important to minimize exposure to mercury. Hence, it is desirable to use low-energy light bulbs that do not contain mercury or other toxic materials.

\section{Solid-State Lighting and LEDs}

CFLs are likely to be a stop-gap measure to replace incandescent lamps, lasting until we have a more efficient, nontoxic source of white light at a reasonable cost. This next generation of home and office lighting will almost certainly be inorganic LEDs.

LEDs are semiconductors in which the light emission comes from a very thin crystalline layer composed of typically two, three, or four elements such as indium gallium nitride (InGaN). This very thin layer, typically only about five atomic layers, or $2 \mathrm{~nm}$, thick, is called a quantum well (see Figure 1). The quantum well of InGaN is sandwiched between two thicker layers of gallium nitride $(\mathrm{GaN})$, one of which, called $n$-type GaN, is rich in negatively charged particles called electrons, and the other, called $p$-type GaN, is rich in positively charged particles called holes. When a voltage, for example, from a battery, is applied across the sandwich, electrons are injected into the InGaN quantum well from the $n$-type $\mathrm{GaN}$, and holes are injected from the $p$-type GaN (see Figure 2). These electrons and holes exist in the InGaN at different energy levels separated by an energy bandgap. When the electrons and holes subsequently meet and recombine, the energy released is given out as light, and the wavelength of the light emitted is equivalent to the bandgap energy. This results in the emission of light of a single color, such as red or green or blue, called monochromatic light. We can change this color by varying the composition of the InGaN quantum well and also by changing the thickness of the quantum well. Scientists are therefore able to make an LED emit light of any desired color. This tailor-made lighting has become possible only recently because of some fundamental advances in materials science, and it is revolutionizing the field of lighting.

\section{The Development of Red LEDs}

The story of the development of LEDs is fascinating and deserves to be much better known, as it illustrates very clearly how basic research on new materials makes it to the marketplace.

The first LED to be made emitted red light, and it was made from GaAsP by Nick Holonyak ${ }^{6}$ in the fall of 1962 , at

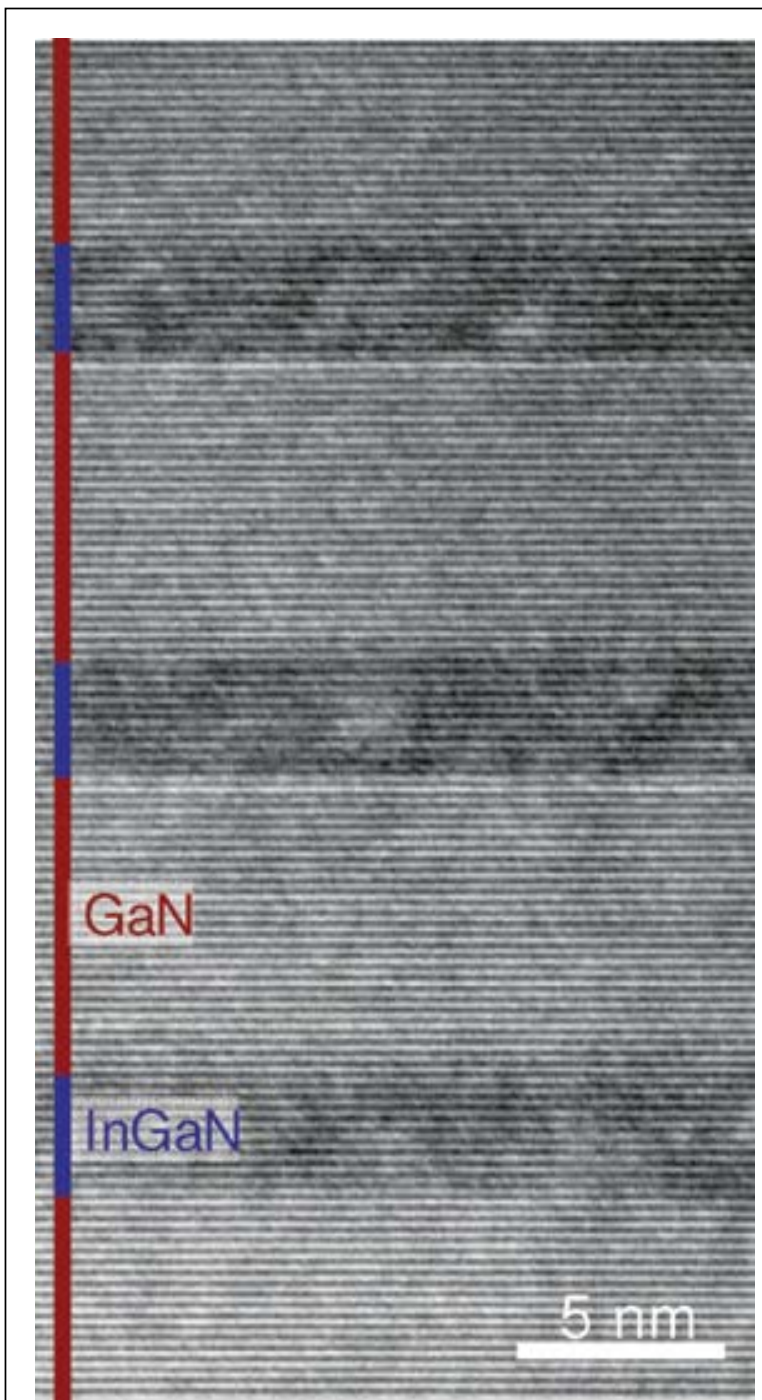

Figure 1. High-resolution transmission electron microscope (0002) lattice fringe image of three InGaN quantum wells separated by GaN barriers (courtesy of T.M. Smeeton, University of Cambridge, Cambridge, UK).

GE's Solid-State Device Research Laboratory in Syracuse, New York. It shone extremely dimly and had an efficacy of only $0.1 \mathrm{~lm} / \mathrm{W}$. Despite this not-very-brilliant start, Holonyak was incredibly determined (the hallmark of a good researcher), and in the February 1963 issue of Reader's Digest, Holonyak is reported as saying: "We believe there is a strong possibility of developing the LED as a practical white source." Holonyak then made the following remarkable prediction: "The lamp of the future might be a piece of metal the size of a pencil point, which will be practically indestructible, will never burn out, and will convert at least 10 times as much current into light as does today's bulb." Indeed, today's white LED is already six times as efficient as a filament light bulb and is on course to be at least 10 times as efficient. Hence, Holonyak's prediction is likely to be fulfilled within the next $5-10$ years.

The research director at GE was not very impressed with Holonyak's red LED, which could be seen only in the dark, so Holonyak, determined to continue his LED research, left and 
went to the University of Illinois. Ten years later, he had doubled the efficacy of his LED, to $0.2 \mathrm{~lm} / \mathrm{W}$, but it could still be seen only in the dark. Undeterred, Holonyak tried a new material, GaAs, and also made a quantum-well LED. Because the carriers (electrons and holes) were confined in a quantum well that was only a few nanometers thick, the chances of them meeting, and recombining to emit light, were greatly enhanced. Ten years later, by 1980, the efficacy of Holonyak's red AlGaAs/GaAs quantum-well LED had leaped by a factor of 10 , to $2 \mathrm{~lm} / \mathrm{W}$.

Holonyak pressed on with materials improvements. Another 10 years on, by 1990 , he had increased the efficacy by a factor of five, to $10 \mathrm{~lm} / \mathrm{W}$, by introducing a quaternary semiconductor: his materials system was now AlInGaP/GaAs. An additional 10 years on, in the year 2000, the quantum-well LED material was changed to AlInGaP/GaP, which produced another 10 times increase in efficacy, to an impressive $100 \mathrm{~lm} / \mathrm{W}$. The efficacy of red LEDs has increased by over five times every 10 years since 1962.

To illustrate this growth, consider red rear bicycle lamps. Traditionally, these are made from small filament light bulbs, emitting white light, with a piece of red plastic in front. The efficacy of the light bulb is about $10 \mathrm{~lm} / \mathrm{W}$. After the light has passed through the red plastic, which filters out colors other than red, the efficacy of red light production is less than $3 \mathrm{~lm} / \mathrm{W}$. However, the efficacy of a red LED, which does not need to be filtered, is $100 \mathrm{~lm} / \mathrm{W}$, a factor of 30 times higher than that of an incandescent bulb with a red filter. Thus, if you have a red LED rear bicycle lamp, your batteries will last about 30 times longer than if you have a traditional rear bicycle lamp with a filament light bulb. In addition, the LED will last 100 times longer than the light bulb.

An important example of energy savings from single-color LEDs is that of traffic lights. The arguments for fitting LED traffic lights (Figure 3) are overwhelming. Denver, Colorado, was one of the first places to realize this in the late 1990s. Since then, more than 48,000 of its red, yellow, and green traffic lights have been converted to LEDs, which has saved the city more than $\$ 800,000$ per year in energy, labor, and materials costs. It has also saved 3,000 t of $\mathrm{CO}_{2}$ emissions per year. Since the end of 2000 , Stockholm has fully converted its traffic lights to LEDs. The result has been a reduction in energy use of $85 \%$, or $5,800 \mathrm{MWh} /$ year, far more than was expected. The average power used per traffic light fell from 70 to $6 \mathrm{~W} .{ }^{14}$ All of Singapore and much of China now have LED traffic lights. A public survey in Singapore after the country had completely replaced its traffic lights with LEDs showed that over $90 \%$ of the public preferred the LED traffic signals. Better visibility at night, better visibility in the rain, and better visibility in direct sunlight were the main reasons given. Most cities in the United States are in the process of replacing their existing lights with LED lights, and about $50 \%$ of the United States now has LED traffic lights. Worldwide, 1.6 million LED traffic lights were in use in 2002, and this value will now be substantially higher. growth methods are used.

\section{The Importance of Gallium Nitride}

Gallium nitride $(\mathrm{GaN})$ is probably the most important new semiconductor material since silicon. The main materials that were known to emit light before the era of GaN are summarized in Figure 4. As shown in Figure 4b, many different materials

Figure 2. Schematic GaN/InGaN quantum-well light-emitting diode (LED) structure together with

Cross-sectional TEM

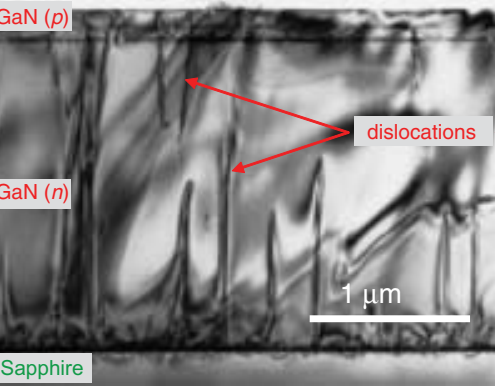

Plan-view TEM

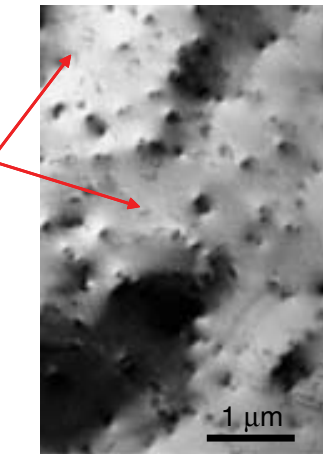

transmission electron micrographs showing the high density of threading dislocations resulting from the growth of $\mathrm{GaN}$ on sapphire. The lattice mismatch for the growth of $\mathrm{GaN}$ on (0001) sapphire is $16 \%$,

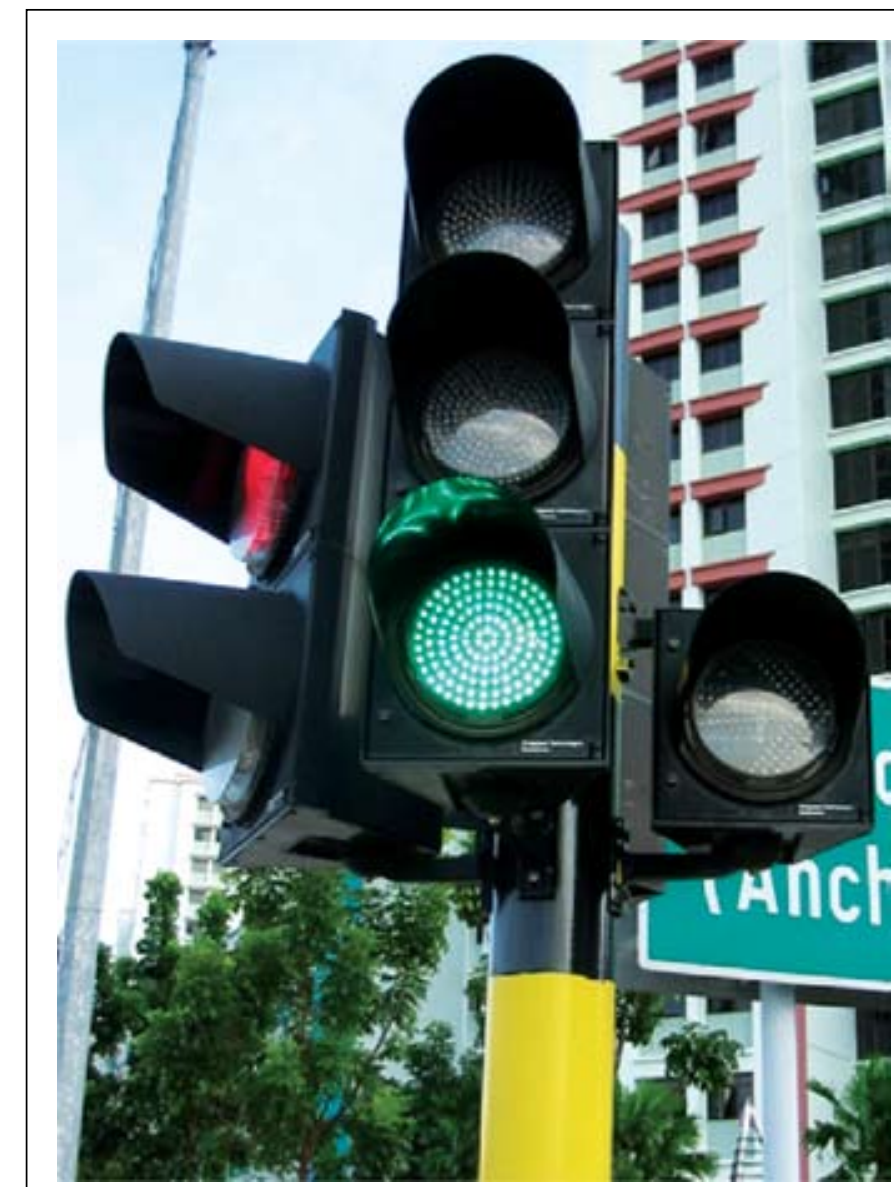

Figure 3. LED traffic lights. 
were required to go from infrared (InAs) through blue ( $\mathrm{ZnSe})$. However, despite major research efforts worldwide, $\mathrm{ZnSe}$ blue light-emitting devices have never worked, with one problem due to the defects in the material that quench the light emission. Hence, bright blue LEDs could not be made. Green LEDs were also a problem because, although both $\mathrm{GaP}$ and AlAs emit green light, both have an indirect bandgap (which means that momentum must be supplied to the electrons and holes for them to recombine), so the light emitted is weak. Hence, before the advent of GaN, bright LEDs ranged from infrared through yellow, but bright green, blue, and white LEDs were not available.

Gallium nitride, and its sister materials indium nitride ( $\mathrm{InN}$ ) and aluminum nitride (AlN), changed the situation dramatically. As Figure 4a shows, InN has a bandgap of about $0.7 \mathrm{eV}$ and emits in the infrared, at one end of the visible spectrum. GaN has a bandgap of $3.4 \mathrm{eV}$ and emits in the near-UV range, at the other end of the visible spectrum. By mixing InN and $\mathrm{GaN}$, both of which have the same hexagonal crystal structure, any color in the visible spectrum can, in principle, be produced, as well as infrared and near-UV radiation. For example, blue and green light is produced from $\operatorname{In}_{x} \mathrm{Ga}_{1-x} \mathrm{~N}$ alloys having indium fractions that are $10 \%$ and $20 \%$ of the group III metal content, respectively. For the first time in history, we have a semiconductor material, InGaN, that can, in principle, emit bright light of any color in the visible spectrum. However, in practice, it is found that the intensity of light emission from InGaN is low at high indium content, for reasons that are not fully understood. This means that, although InGaN emits blue light strongly, its green light emission is less intense, and its red light emission is weak.

If $\mathrm{GaN}$ is mixed with AlN (bandgap $6.2 \mathrm{eV}$ ) to form $\mathrm{Al}_{x} \mathrm{Ga}_{1-x} \mathrm{~N}$, then $\mathrm{UV}$ light ranging from near-UV through to deep-UV light can be produced. (The focus here is on visible lighting, but it is worth noting in passing that deep-UV radiation has many important applications including water purification, air purification, and the detection of biological agents.) $\mathrm{InN}$, $\mathrm{GaN}$, and AlN are collectively known as III-nitrides. These materials do not exist in nature, and the creation of this semiconductor family that emits light over such a huge range of important wavelengths is a major breakthrough in materials science.

The first prototype bright blue LED was based on GaN containing a very thin layer of InGaN, called an InGaN quantum well, with about $10 \%$ In. It was demonstrated in November 1993 by Shuji Nakamura in his small laboratory at Nichia Chemical Industries in Japan. In 2006-just 13 years later-over \$4 billion worth of GaN-based LEDs were sold worldwide. Remarkably, this was greater than the total sales of gallium arsenide (GaAs) devices in 2006, even though
GaAs devices have been around for much longer and most cell phones contain a GaAs chip. The speed to market of GaN LEDs has been amazing and has resulted because these LEDs fulfill a real market need. However, the fact that GaNbased LEDs emit light at all is due to extreme scientific good fortune.

\section{Why Do Highly Defective GaN-Based Materials Emit Brilliant Light?}

Until a few years ago, the answer to this question seemed clear. The world's GaN scientists believed they knew why GaN devices emitted intense light even though they had a high dislocation density: nanometer-scale indium-rich clusters formed in the InGaN quantum wells that localized the carriers (the electrons and holes) so that they could not diffuse to dislocations. The evidence for this explanation came from thermodynamics and electron microscopy.

Most commercial LEDs are grown on sapphire substrates, and the lattice mismatch (difference in atom spacing) between $\mathrm{GaN}$ and sapphire is a massive $16 \%$. This misfit results in a high density of defects called threading dislocations, in which a typical density of threading dislocations passing through the active InGaN quantum wells is 5 billion per square centimeter $\left(5 \times 10^{9}\right.$ $\mathrm{cm}^{-2}$ ) (see Figure 2). Dislocations in GaN are known to be nonradiative recombination centers that should quench the light emission. Indeed, if the dislocation density in other semiconductors, for example, GaAs, exceeds 1000 per square centimeter $\left(10^{3} \mathrm{~cm}^{-2}\right)$, the light emission is quenched.

Thermodynamic calculations showed that $\mathrm{InGaN}$ is unstable and should decompose into In-rich and In-poor regions. ${ }^{15}$ 
Critically, high-resolution electron micrographs showed that InGaN quantum wells contain strained regions on a nanometer scale, ${ }^{16}$ and electron energy loss spectroscopy showed that these regions are indium-rich. ${ }^{17}$ Because the bandgap of $\mathrm{InN}$ is less than that of $\mathrm{GaN}$, indium-rich regions in an InGaN quantum well will confine the electrons and holes and prevent them from diffusing to dislocations. Severe doubt was cast on this theory in 2003 when observation using a low electron dose revealed no gross indium clustering. Instead, the indium-rich clusters were being produced by electron-beam damage within the electron microscope and were thus just an artifact of the observation technique. ${ }^{18}$ In addition, more sophisticated thermodynamic calculations, which took into account the fact that the InGaN quantum wells were strained, suggested that the strain should suppress the decomposition and that InGaN should be a homogeneous random alloy up to an indium content of at least $40 \% .{ }^{19}$ Hence, the bright light emission from InGaN cannot be due to the formation of indium-rich clusters. So the puzzle remained: Why do InGaN quantum wells emit brilliant light when the dislocation density is so high? This controversy provoked two special symposia at international conferences in 2005 and a special issue of Philosophical Magazine in 2007..$^{20}$

The consensus now emerging (see the articles in Reference 20 ) is that the high brightness of GaN-based LEDs might be due to a fortunate and unexpected interface effect: monolayerheight interface steps on the InGaN quantum wells. Researchers now believe that InGaN is a random alloy in quantum wells with compositions of up to at least $30 \%$ indium. Recent threedimensional (3-D) atom probe studies, which do not use an electron beam for imaging, confirm that $\mathrm{InGaN}$ is indeed a random alloy. ${ }^{21}$ However, interestingly, transmission electron microscope results suggest that the InGaN quantum wells contain monolayer-height interface steps, ${ }^{22}$ and this has also recently been confirmed by $3-\mathrm{D}$ atom probe studies. Because the quantum wells are strained and because of the high piezoelectric effect in GaN, a monolayer interface step produces an additional carrier confinement energy of about $3 \mathrm{kT}$ at room temperature, where $k$ is the Boltzmann constant and $T$ is temperature. This is sufficient to localize the carriers (for a review, see Reference 23).

\section{Solid-State White Light}

Whereas LEDs and OLEDs emit light of a single color in a narrow band of wavelengths, we need white light for a huge range of applications, including home and office lighting, and obtaining white light from LEDs and OLEDs presents a challenge. In fact, no white OLED for lighting is currently commercially available, ${ }^{8}$ and it is unclear if and when this will happen.

There are various ways of obtaining white light from inorganic LEDs. Some of these involve the use of colored LEDs coated with phosphors. I will call such LEDs "white LEDs," as is standard practice. Phosphors are, in fact, highly important for some types of white LEDs.

\section{Phosphors for LEDs}

Most phosphors have been developed for use with fluorescent tubes or CFLs that emit UV radiation, and hence, they have not been optimized for use with LEDs emitting in the visible spectrum. The first commercially available white LED was based on an InGaN chip emitting blue light at a wavelength of $460 \mathrm{~nm}$ that was coated with a cerium-doped yttrium aluminum garnet (YAG) phosphor layer that converted some of the blue light into yellow light. ${ }^{24}$ Both the chip and the phosphor are nontoxic, so the white LED is not toxic (unlike CFLs).
The blue LED plus yellow phosphor combination just outlined gives a cool white light. For home and office lighting, a warmer white light is desirable, which means adding some red light to the blue plus yellow. Unfortunately, very few red phosphor materials are available for excitation using blue or nearUV light, and those that are available have a low efficiency. Novel phosphors for LED lighting are being produced, ${ }^{25}$ but these are at an early stage, and further research is needed in this area (see Reference 26 for further details).

\section{How to Make Solid-State White Light}

There are a number of ways to use GaN-based LEDs to make white light:

1. Blue LED and yellow phosphor. As stated previously, nearly all white LEDs sold today use a blue GaN/InGaN LED plus a yellow phosphor. The blue LED chip is covered with a thin layer of a phosphor that emits yellow light when excited by the blue light. The phosphor layer is sufficiently thin that some blue light is transmitted through it, and the combination of blue and yellow produces a cool white light. The white LEDs used as front bicycle lights (Figure 5); in large display screens (Figures 6 and 7); as the interior lighting in cars, buses, trains, and planes; or as the exterior lighting on buildings, for example, all use blue LEDs covered with a yellow phosphor.

2. Red plus green plus blue LEDs. This method, mixing red, green, and blue (RGB) LEDs is the obvious way to produce white light. However, this approach has three basic problems. The first is that the efficiency of green LEDs is much less than that of red and blue LEDs, for reasons that are not yet understood (this is known as the "green gap" problem). Hence, the overall efficiency of this method is limited by the low efficiency of the green. Second, the efficiencies of red, green, and blue LEDs change over time at different rates. Hence, if a high-quality white light is produced initially, over time, the quality of the white light degrades. However, this process is slow and can be corrected using automatic feedback. Third, because the emission peaks of LEDs are narrower than those of most phosphors, red plus green plus blue LEDs will give a poorer color rendering than red plus green plus blue phosphors. This problem can be minimized by a careful choice of LED emission wavelengths, and of course, more than three different color LEDs can be used for better coverage of the visible spectrum. In particular, using four LEDs - red, yellow, green, and blue - can give a good color rendering.

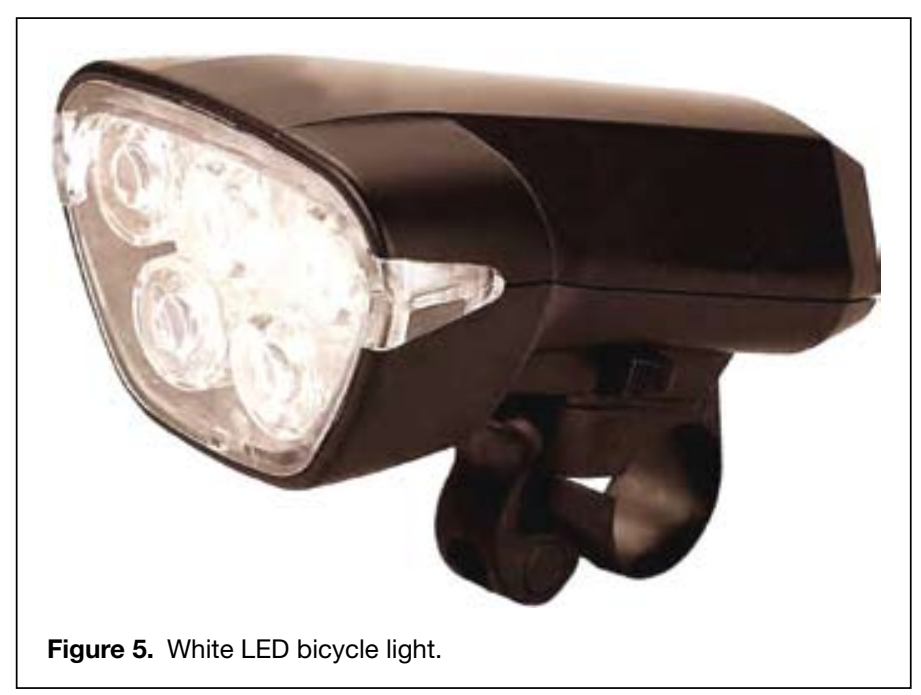




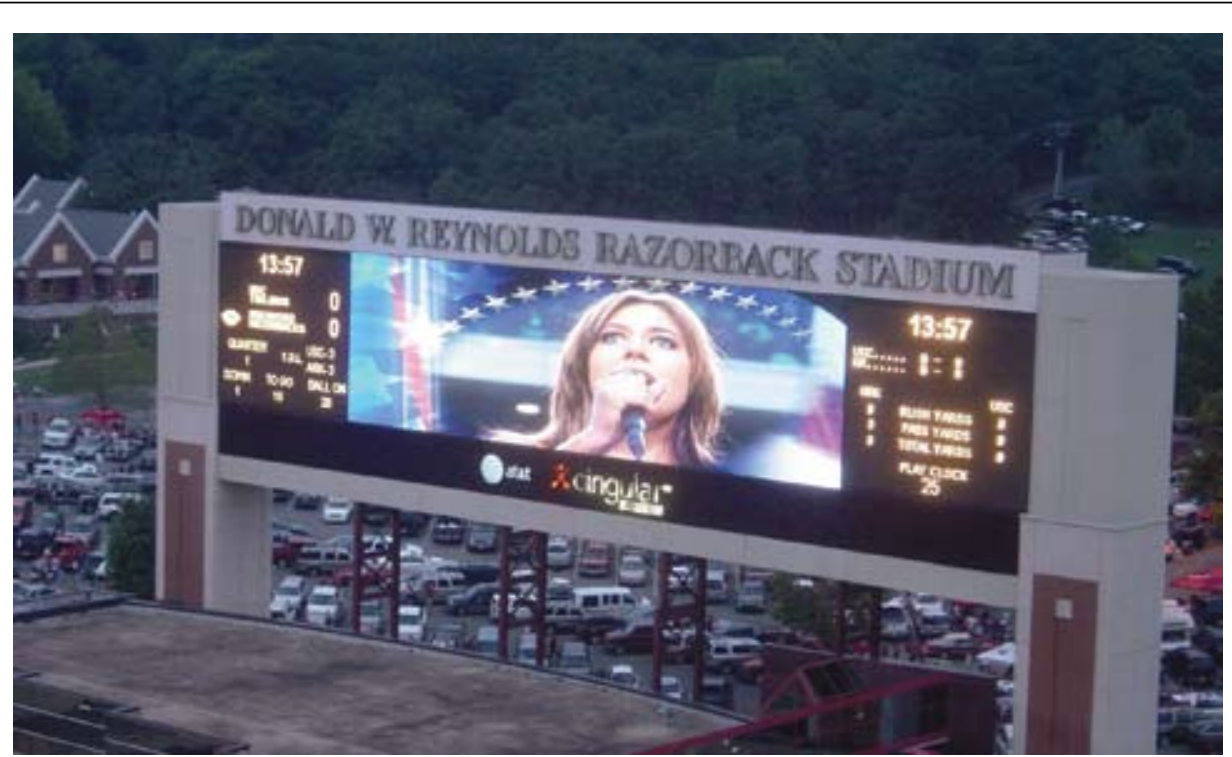

Figure 6. One of the largest LED screens in the world: the Donald W. Reynolds Razorback Stadium replay screen in Arkansas. The screen contains 2.5 million LEDs.
3. Red, green, and blue quantum dots in a single LED. It is possible to produce a single LED with quantum dots of InGaN of different sizes and compositions so that white light is emitted. This is a recent development, and the efficiency, reproducibility, and lifetime of these LEDs are not yet known.

4. Near-UV or blue LED plus red, green, and blue phosphors. As already discussed, blue LEDs covered with yellow phosphors give a rather cool white light. This is fine for many applications (e.g., displays, lighting in cars, buses, yachts, key-rings, and cell phones), but the quality of light is probably not good enough for home lighting, for which a warmer white light containing some red light is desirable. Such warm white LEDs (blue LEDs plus yellow and red phosphors) are available commercially now. However, the efficiency with which existing red phosphors are excited using blue light is much less than that using near-UV light; hence, a better route to higher quality white light might be to use a near-UV LED plus red, green, and blue phosphors. There are no dangers in using a near-UV LED as thick phosphor layers would be used so that no near-UV light would be transmitted, in much the same way as the phosphor coating on fluorescent tubes and CFLs prevents the transmission of UV light.

\section{Limitations of LED Lighting}

Although existing markets for LEDs are large, the real prize is home and office lighting. If GaN-based LEDs are so good, what is preventing their widespread use in our homes and offices? There are five main factors: efficiency, heat management, color rendering, lifetime, and cost.

\section{Efficiency}

Table I compares the efficiencies and efficacies of various forms of lighting, including white LEDs. For high light output, for example, $1000 \mathrm{~lm}$ per LED, the LEDs need to be run at a high drive current $(350 \mathrm{~mA}$ is a standard drive current for highpower white LEDs). The maximum efficiency of a commercial high-power white LED is currently about $30 \%(100 \mathrm{~lm} / \mathrm{W}$ efficacy). This is six times greater than the efficiency of a filament

Table I: Efficiencies and Efficacies of Various Forms of Commercially Available Lighting in 2007.

\begin{tabular}{|l|c|c|}
\hline \multicolumn{1}{|c|}{ Type of Light Source } & Efficiency (\%) & Efficacy (Im/W) \\
\hline Incandescent light bulb & 5 & 15 \\
\hline Long fluorescent tube & 25 & 80 \\
\hline Compact fluorescent lamp (CFL) & 20 & 60 \\
\hline High-power white LEDs & 30 & 100 \\
\hline Low-power white LEDs & 50 & 150 \\
\hline Sodium lamp (high-pressure) & 45 & 130 \\
\hline White LEDs (10-year target) & 60 & 200 \\
\hline
\end{tabular}


light bulb and $50 \%$ better than that of a compact fluorescent lamp. However, at a lower drive current of $20 \mathrm{~mA}$ (a standard low-drive current) and therefore less total light output (typically $10 \mathrm{~lm}$ ), LEDs with an efficiency of $50 \%$ are commercially available. We can expect an efficiency of $50 \%$ to be reached for higher drive currents (for example, $350 \mathrm{~mA}$ ) in the next few years. We will then have a light source that is 10 times as efficient as filament light bulbs, three times as efficient as compact fluorescent lamps, twice as efficient as fluorescent tubes, and more efficient than even a sodium lamp (which has poor color rendering and is mainly used for low-quality street lighting). A target of at least $60 \%$ efficiency might be possible in the next 10 years or so. It is unlikely that other forms of lighting, for example, fluorescent tubes and CFLs, will increase their efficiency significantly in the future given that their technology is mature.

The factors currently limiting the efficiency of GaN LEDs are complex and not well understood. Figure 8 shows a plot of the internal quantum efficiency (IQE) of GaN-based quantum wells versus wavelength, using the best IQE values reported. (The IQE is the ratio of the number of photons out to the numbers of photons in, if excited by a laser, or to the number of electrons in, if excited electrically.) The shape of this curve is not understood theoretically. Improving efficiencies further at all wavelengths requires some in-depth basic science. However, it is clear from Figure 8 and Table I that existing blue and white LEDs are already efficient light sources.

\section{Heat Management}

Although the best high-power white LEDs have an efficacy of about $100 \mathrm{~lm} / \mathrm{W}$ at $350 \mathrm{~mA}$, many commercial high-power white LEDs operate at an efficacy of about $75 \mathrm{~lm} / \mathrm{W}$ at $350 \mathrm{~mA}$, which is about $25 \%$ efficient. This means that, although LEDs stay cool relative to incandescent light bulbs, $75 \%$ of the input power is dissipated as heat. If the LED becomes too hot, then its lifetime decreases. Heat management is therefore an important issue in many applications of high-power LEDs (the materials issue associated with heat management include degradation of the contacts and the generation of defects). ${ }^{27}$ For example, in

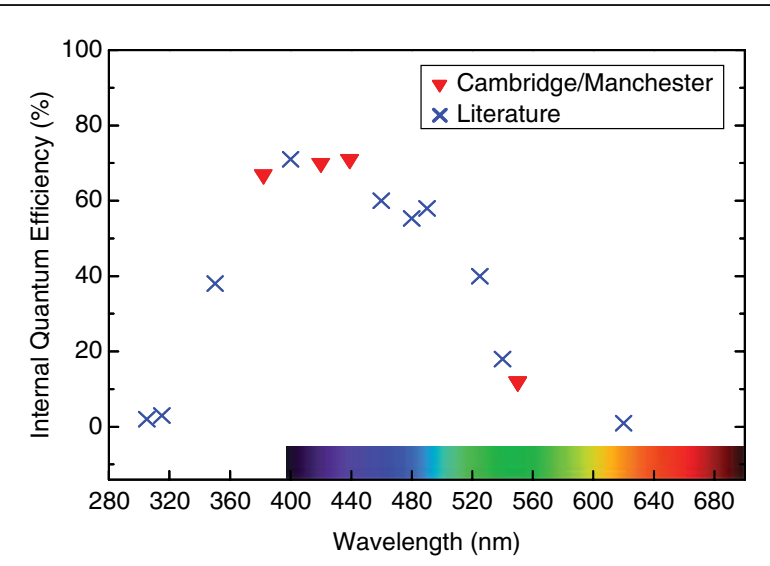

Figure 8. Plot of the internal quantum efficiency (IQE), measured using photoluminescence $(\mathrm{PL})$, versus wavelength of III-nitride quantum-well structures. The points plotted are the highest IQE values reported in the literature. Triangles mark results on Cambridge-grown structures, assessed using $\mathrm{PL}$ at Manchester. Crosses mark results reported in References 30-35. the LED car headlamps that BMW and Lexus are introducing, heat management has been a key issue to solve.

Fortunately, the problem of heat management will significantly decrease in the next few years when white LEDs reach an efficacy of $150 \mathrm{~lm} / \mathrm{W}$, which corresponds to $50 \%$ efficiency, as less heat is then emitted. Hence, higher LED efficiency is not only important for saving energy and carbon emissions; it will also greatly facilitate heat management.

\section{Color Rendering}

Nearly all commercial white LEDs are blue LEDs coated with a yellow phosphor. These emit a cool white light that might not be acceptable for home lighting. If the various routes to higher quality white LED lighting mentioned earlier prove to be successful, we could then mimic the visible spectrum of sunlight, giving high-quality "natural" lighting in our homes and offices, in which clothing, lipstick, and skin colors would look the same as outdoors. Apart from the public preference for this natural lighting, there might well be health benefits. Humankind developed in natural lighting, and our bodies are adapted to this. The 24-h cycle of our internal body clock (our circadian rhythm) determines not only our sleep pattern, but also such functions as brainwave activity, hormone production, and cell regeneration. There is increasing evidence that, in addition to light intensity, light color is also an important factor controlling the degree to which our internal body clock is reset. ${ }^{28}$ At current rates of progress, white LEDs that both are highly efficient and also have excellent color rendering should be available within the next 10 years. The progress is likely to be incremental, with light of better quality becoming available each year.

\section{Lifetime}

Red LEDs are known to have a lifetime of 100,000 h (11 years). Many manufacturers claim a 100,000-h lifetime for their white LEDs (blue LED plus yellow phosphor), but in many cases, independent studies have shown that this claim is not true. The basic blue-emitting chip does have a lifetime of at least $100,000 \mathrm{~h}$; the problem lies in the packaging and in the use of cheap, poor-quality components.

One problem is that the epoxy resin used in the LED encapsulation process can become very inflexible when exposed to heat and to blue light. When the LED is switched on, all the components heat up, and thermal expansion can cause the contact wires to move relative to the LED chip and the frame. If the cured epoxy resin is inflexible, the contact wires can become detached. The use of a high-grade silicone polymer instead of epoxy resin eliminates this problem and others. We can expect that, with good packaging, as is now being employed by the best LED manufacturers, the lifetime of white LEDs should be about $100,000 \mathrm{~h}$.

\section{Cost}

Cost is probably the major factor limiting the widespread use of white LEDs in our homes and offices. GaN-based LEDs are significantly more expensive than filament light bulbs or CFLs. However, the cost is continually decreasing. White LEDs are currently grown on 2-in.- (5-cm-) diameter sapphire $\left(\mathrm{Al}_{2} \mathrm{O}_{3}\right)$ or $\mathrm{SiC}$ substrates. Increasing the diameter of these substrates will reduce costs because edge effects will become relatively less important, and the cost of processing a $4-\mathrm{in} .(10-\mathrm{cm})$ wafer is much the same as processing a $2-i n .(5-\mathrm{cm})$ wafer, but four times as many LEDs can be obtained from a 4-in. (10-cm) wafer.

A more dramatic cost reduction might be achieved by growing GaN-based LEDs on 6-in. (150-mm) silicon wafers. Six-inch (150-mm) Si wafers cost much less than 2-in. (5-cm) sapphire or $\mathrm{SiC}$ wafers. In addition, 6-in. (150-mm) processing 
lines are relatively common in the electronics industry, whereas 2- and 4-in. (5- and 10-cm) facilities are rare. One hundred fifty thousand LEDs could be grown on a single 6-in. (150-mm) wafer. We can therefore expect substantial reductions in the future cost of white LEDs.

\section{White Solid-State Lighting: The Present}

White LEDs are already widely used, for example, as backlighting in cell phones; as interior lighting in aircraft, cars, and buses; and as bulbs in flash lights. They are also being fitted on airport runways: traditional lighting on runways lasts for about six months, and the runway has to be closed to replace it, at considerable cost. LED lighting should last for 10 years, giving significant operational savings. Audi A6 and A 8 cars are using white LEDs as front daytime running lights, and BMW and Lexus are introducing white LEDs in their top-of-the-line car head lamps. LEDs are also being increasingly used for the flashes in camera phones. For example, sales of Philips Lumileds Flash LEDs for camera phones have gone from zero to 100 million units in less than three years.

White (and colored) LEDs are increasingly being used to illuminate the fronts of buildings. For example, on October 23, 2006, it was announced that the front of Buckingham Palace in London would be illuminated at sunset every day during winter for the benefit of tourists. Apparently, the Queen had personally chosen white LEDs because of their low energy consumption, long life, and low maintenance. The power consumed in illuminating the whole of the front of Buckingham Palace using white LEDs is less than that used in running an electric kettle $(2.8 \mathrm{~kW})$. White and colored LEDs are widely used in displays around the world (see Figures 6 and 7). A large emerging new market is LED backlighting for liquid crystal displays for televisions and computer screens, replacing fluorescent backlighting: for example, Showa Denko is expanding to make 200 million GaNbased LEDs per month by the end of 2008 compared to 60 million per month in mid-2007, mainly for the LED backlighting market.

\section{Key Materials Research Challenges}

If white LEDs are to become the lighting of choice in our homes and offices, then the following key materials problems will need to be solved (see also Reference 26):

\section{Increased Efficiency of Green LEDs}

As previously stated, this is known as the "green gap" problem, and it is not well understood. Recent work has shown that, in green-emitting InGaN, the InGaN quantum wells often break up into network structures and the threading dislocations are mostly physically separated from the active regions of the quantum wells. ${ }^{29}$ Optimization of the quantum-well network structures might well enable an increase in the efficiency of green LEDs.

\section{Increased Efficiency of Blue and Near-UV LEDs}

Blue LEDs are the basis of both the cool and the warm white LEDs available today. The IQE of blue emitters is about $70 \%$ (see Figure 8). This value is already high, but if the IQE can be increased to $90 \%$, then we can both increase the external efficiency significantly and also help to solve problems of thermal management.

Near-UV LEDs are more efficient than blue LEDs at exciting a number of phosphors, particularly red phosphors. NearUV 380-nm LEDs also have a high IQE of $67 \%$ (see Figure 8), but again, increasing the value to $90 \%$ would facilitate highquality white lighting based on a near-UV LED plus red, green, and blue phosphors.

\section{Dislocation Reduction}

As previously described, blue InGaN-based LEDs emit brilliant light even though the dislocation density is high. However, the efficiency is even higher if the dislocation density is reduced. Free-standing low-dislocation-density GaN substrates are expensive, so a key research challenge is to reduce the dislocation density substantially in situ in the growth reactor by optimizing such factors as the growth conditions and the use of interlayers.

\section{Nonpolar and Semipolar GaN}

Virtually all commercial GaN-based LEDs are grown in the [0001] direction. This is a polar direction, so there is an electric field across the InGaN quantum well that keeps the electrons and holes apart and, hence, reduces the rate of recombination and light emission. Growth in a nonpolar (or semipolar) direction should eliminate this effect, thus enhancing the efficiency of light emission. However, unless expensive free-standing nonpolar $\mathrm{GaN}$ substrates are used, the defect density increases, and hence, the IQE decreases instead of improving. Further research is required to grow nonpolar $\mathrm{GaN}$ with low defect densities.

\section{Improved p-GaN}

The holes in $p$-type GaN have a low mobility and a low concentration. This reduces the LED efficiency. Further research is required to improve the quality of $p-\mathrm{GaN}$.

\section{Novel Wide-Bandgap Semiconductors}

Fundamental research on novel wide-bandgap semiconductors is required as these materials might be even more efficient than GaN-based devices. $\mathrm{ZnO}$ is currently receiving much attention, but efficient $p$-doping of $\mathrm{ZnO}$ is proving to be a major problem. $\mathrm{ScN}$ is a potentially promising novel nitride, ${ }^{36}$ but further work is required on new wide bandgap semiconductors.

\section{Novel Phosphors}

As mentioned earlier, most phosphors were developed for use with UV-emitting fluorescent tubes. There is an urgent need for new phosphors optimized for use with blue and near-UV LEDs.

Assuming that adequate funding is made available to address the key materials research challenges outlined, progress in solving these issues will have a significant effect on the future use of white LEDs in home and office lighting.

\section{White LEDs for Lighting: The Next 5-10 Years}

The main current market for LEDs is in displays and backlighting for devices such as cell phones. The next large market will be automotive lighting. There are 600 million cars on Earth. Last year, 60 million cars and 40 million motorbikes were made, and this number is rising rapidly. The power consumption for lighting in a typical car is $370 \mathrm{~W}$. By using LEDs, this value can be reduced to $70 \mathrm{~W}$. If $50 \%$ of cars used LEDs instead of halogen lamps just for their low-beam headlamps, the electricity savings would be 110 million $\mathrm{kWh}$. Cool white LEDs (blue LED plus yellow phosphor) are fine for both car interior lighting and exterior daytime running lights and headlamps. Although white LEDs are more expensive than conventional car lights (internal and external), the substantially longer lifetime coupled with fuel savings (the energy for the lighting comes from the fuel) means that, even at their current price, white LEDs are being increasingly used in cars. In the next five years, white LED lighting is likely to be the lighting of choice in all cars.

The use of white LEDs for home lighting is currently extremely small. Warm white LEDs are now available, based 
on blue LEDs plus yellow and red phosphors. However, these warm white LEDs are less efficient than cool white LEDs because of the low efficiency of red phosphors excited by blue light; they are also more expensive. Higher quality warm white LEDs, with almost perfect color rendering, need further research but should be available in the next five years.

As previously mentioned, a key issue for the use of LED lighting in homes and offices is cost. The total costs of ownership of a light bulb, combining the purchase cost plus running costs, at $8 \mathrm{~h}$ per day, are listed in Table II for one and five years, assuming the current costs of electricity to be $\$ 0.1 \mathrm{kWh}$ for households in the United States and $\$ 0.2 \mathrm{kWh}$ for households in the United Kingdom. It is clear that warm white LED lighting is not yet economically attractive for home lighting. In 2002,

years we can expect today's warm white LEDs to be replaced by higher quality white LEDs giving out natural lighting, similar to sunlight. Further research is needed to develop these LEDs, but they are likely to be popular with customers for the health reasons mentioned earlier. Such white LEDs giving out natural light are likely to be commercially available in the next 10 years.

\section{White LEDs for Lighting: The Next 10-20 Years}

The OIDA 2002 Roadmap $^{37}$ predicted that, by 2007, white LEDs would have an efficacy of $75 \mathrm{~lm} / \mathrm{W}$ and a light output of $200 \mathrm{~lm} / \mathrm{lamp}$. Both of these milestones have been achieved and, in fact, exceeded. For example, a $115 \mathrm{~lm} / \mathrm{W}$ cool white LED is commercially available today $(1 \mathrm{~mm} \times 1 \mathrm{~mm}$ chip, $350 \mathrm{~mA})$. The Roadmap predicts that, by 2012, a white LED with an efficacy of $150 \mathrm{~lm} / \mathrm{W}$ and a light output of $1000 \mathrm{~lm} / \mathrm{lamp}$ will be achieved. We are, indeed, on course to achieve these milestones. Finally, the Roadmap predicts that, by 2020 , a white LED with an efficacy of $200 \mathrm{~lm} /$ $\mathrm{W}$ will be available.

The updated 2007 Roadmap ${ }^{38}$ predicts the efficacy of a commercial cool white LED to be $113 \mathrm{~lm} /$ $\mathrm{W}$ in $2010,135 \mathrm{~lm} / \mathrm{W}$ in 2012 , and $168 \mathrm{~lm} / \mathrm{W}$ in 2015 . In fact, the

the U.S. Department of Energy and the Optoelectronics Industry Development Association (OIDA) published a Roadmap for solid-state lighting. This Roadmap gave the 2002 costs of various types of lamps in dollars per kilolumen as 0.4 for incandescent light bulbs, 1.5 for long fluorescent tubes, and 200 for white LEDs. ${ }^{37}$ This Roadmap was updated in March $2007,{ }^{38}$ and the cost of cool white LEDs is given there as $\$ 40$ per kilolumen. In fact, the field is moving so fast that some of the values in this report are already out of date; the cost of white LED lighting is now less than $\$ 20$ per kilolumen. Most people will consider only the capital cost when buying light bulbs for homes, some will consider capital plus running costs over one year, and a few will consider capital costs plus running costs over five years. On this basis, and using the values just given and Table II, it is clear that, today, white LED lighting in homes is a niche market: LEDs will mainly be fitted in locations where the 100,000-h lifetime is important, for example, in inaccessible places.

Over the next five years, we can expect warm white LEDs with an efficacy of at least $130 \mathrm{~lm} / \mathrm{W}$ to become available. The electricity cost for one year at $8 \mathrm{~h} /$ day and today's U.S. cost of electricity of $\$ 0.1 \mathrm{kWh}$ will then be only $\$ 2$. However, if LEDs are to compete with CFLs in terms of the total cost of ownership over one year, then the capital cost of an LED lamp must be less than $\$ 4$, which is a challenge. However, if we take the total cost of ownership over 5 years, then the LED electricity cost is $\$ 10$, and the total cost of ownership is less than that of a CFL if the LED price is less than $\$ 18$, which is easily achievable. In addition, white LEDs contain no toxic materials like mercury. We can therefore expect that white LEDs will enter the home lighting market strongly in the next five years, provided that an efficacy of about $130 \mathrm{~lm} / \mathrm{W}$ can be obtained.

In the next 10 years, the efficiency of white LEDs will continue to increase, with dramatic energy savings. For example, at an efficacy of $150 \mathrm{~lm} / \mathrm{W}$, a white LED with light output equivalent to that of a $60-\mathrm{W}$ incandescent light bulb could be left on all year for $24 \mathrm{~h}$ per day at an electricity cost of only $\$ 5$ (at today's U.S. electricity cost of $\$ 0.1 \mathrm{kWh}$ ). Also in the next 10 prediction of $113 \mathrm{~lm} / \mathrm{W}$ in 2010, published in May 2007, was exceeded later in 2007 , with the aforementioned commercial availability of a cool white LED having an efficacy of $115 \mathrm{~lm} / \mathrm{W}$ at $350 \mathrm{~mA}$. Again, this indicates the rapid progress being made with inorganic LEDs, and it raises expectations that the other future predictions for inorganic LEDs will also be met.

The situation with OLEDs is much less clear. The OIDA 2002 Roadmap for OLEDs gave targets for 2007 that have not been met, and no white OLEDs for lighting are commercially available, unlike the situation with white LEDs. The updated 2007 OLED Roadmap ${ }^{38}$ states: "Today, the efficacy of OLED devices lags behind LED devices. . . . However, the efficacy of OLED products should approach that of the LED products in the latter part of the current forecast [toward 2015]. This reflects the anticipated exponential efficacy improvement of OLED devices as compared to the projected linear improvement in the commercial efficacy of LED devices." It seems inherently unlikely that "anticipated exponential efficacy improvements of OLED devices" will occur between now and 2015, and even if they do, the efficacy of OLEDs will still lag behind that of LEDs in 2015. In addition, once white LEDs are established as the lighting of choice in homes and offices, they might be difficult to displace. For further information on OLEDs for lighting, see Reference 38 and the references contained therein.

It is unlikely that $200 \mathrm{~lm} / \mathrm{W}$ will be achieved using an LEDplus-phosphor combination because of efficiency losses in the phosphor and also efficiency losses in converting high-energy photons from the LED into lower energy photons (the Stokes shift). The solution to this problem is to avoid phosphors and to produce white light by mixing red, yellow, green, and blue (RYGB) LEDs. This cannot be done efficiently at present because, as mentioned earlier, green LEDs are much less efficient than blue and red (the so-called "green gap").

If we can solve the green gap problem, then we should be able to produce white light from RYGB LEDs with an efficacy of at least $200 \mathrm{~lm} / \mathrm{W}$. The energy savings, and carbon dioxide emission savings, will then be even greater than the values 
given at the start of this article, which assume an LED efficacy of $150 \mathrm{~lm} / \mathrm{W}$. In addition, this white light source will be color tunable by the customer to provide mood lighting: houses will have a color control switch in rooms (or a hand-held remote control) that will enable people to wake up to a blue-white light and go to bed with a red-white light, for example.

In 10-20 years' time, if we can meet the materials challenges outlined earlier, LEDs will provide the ultimate light source with the following characteristics:

- ultra-energy-efficient (15 times more than incandescent light bulbs and 5 times more than CFLs);

- ultra-long-lived $(100,000 \mathrm{~h}$ compared to $10,000 \mathrm{~h}$ for CFLs and $1000 \mathrm{~h}$ for incandescents);

- environmentally friendly with no toxic mercury;

- inexpensive;

- natural, similar to sunlight, for our health and wellbeing; and

- tunable (with the ability to provide mood lighting of any desired color or shade of white).

Indeed, in 10-20 years' time, LED lighting will probably be the dominant form of lighting in homes, offices, cities, and transport throughout the world.

\section{Acknowledgments}

The author is grateful to a number of people for their helpful comments on this article, particularly Dr. Andrew Phillips, Dr. Ted Thrush, and Clifford McAleese, and to Dr. Dandan Zhu for help with the figures.

\section{References}

1. Building Energy Databook 2006 (Energy Efficiency and Renewable Energy, U.S. Department of Energy, Washington, DC, 2006; http://buildingsdatabook. eren.doe.gov) (accessed January 2008).

2. Navigant Consulting, U.S. Lighting Market Characterization Volume 1: National Lighting Inventory and Energy Consumption Estimate (U.S. Department of Energy, Washington, DC, September 2002; www. eere.energy.gov/buildings/info/documents/pdfs/lmc_vol1_final.pdf) (accessed January 2008).

3. Light's Labour's Lost: Policies for Energy-efficient Lighting (International Energy Agency, Paris, France, 2006)

4. Key World Energy Statistics 2007 (International Energy Agency, Paris, France, 2007).

5. Environ. Build. News 16 (2007)

6. N. Holonyak, S.F. Bevacqua, Appl. Phys. Lett. 1, 82 (1962).

7. B. Johnstone, Brilliant!: Shuji Nakamura and the Revolution in Lighting Technology (Prometheus Books, New York, 2007).

8. Basic Research Needs for Solid-State Lighting. Report of the Basic Energy Sciences Workshop on Solid-State Lighting (Office of Basic Energy Services, U.S. Department of Energy, Washington, DC, May 2006; http://www.er.doe.gov/ bes/reports/files/SSL_rpt.pdf) (accessed January 2008).

9. Strategies in Light, High-brightness LED Market Review and Forecast 2005 (July 2005; http://downloads.peannet.com/pnet/research/66/hbled 2005.pdf) (accessed January 2008).
10. M. Pope, H.P. Kallmann, P. Magnante, J. Chem. Phys. 38, 2042 (1963).

11. Organic Light Emitting Diodes (OLEDs) for General Illumination Update 2002, An OIDA Technology Roadmap (OIDA, Washington, DC, 2002).

12. M. Goetzeler, Global Business Summit for the Environment (B4E); United Nations Environment Program (UNEP), Singapore, 18 April 2007.

13. Mercury Emissions from Coal-Fired Power Plants: The Case for Regulatory Action (Northeast States for Coordinated Air Use Management, Boston, MA, 2003; http://www.nescaum.org/documents/rpt031104mercury.pdf) (accessed January 2008)

14. LEDs in Traffic Lights in Stockholm (Centre for the Analysis and Dissemination of Demonstrated Energy Technologies, OECD/IEA, Paris, 2002).

15. I.C. Ho, G.B. Stringfellow, Appl. Phys. Lett. 69, 2701 (1996).

16. Y. Narukawa, Y. Kawakami, M. Funato, S. Fujita, S. Nakamura, Appl. Phys. Lett. 70, 981 (1997)

17. H.K. Cho, J.Y. Lee, N. Sharma, C.J. Humphreys, G.M. Yang, C.S. Kim, J.H. Song, P.W. Yu, Appl. Phys. Lett. 79, 2594 (2001).

18. T.M. Smeeton, M.J. Kappers, J.S. Barnard, M.E. Vickers, C.J. Humphreys, Appl. Phys. Lett. 83, 5419 (2003).

19. S.Y. Karpov, MRS Internet J. Nitride Semicond. Res. 3, 16 (1998).

20. Philos. Mag. 13, 87 (2007)

21. M.J. Galtrey, R.A. Oliver, M.J. Kappers, C.J. Humphreys, D.J. Stokes, P.H Clifton, A. Cerezo, Appl. Phys. Lett. 90, 061903 (2007).

22. D.M. Graham, A. Soltani-Vala, P. Dawson, M.J. Godfrey, T.M. Smeeton, J.S. Barnard, M.J. Kappers, C.J. Humphreys, E.J. Thrush, J. Appl. Phys. 97, $103508(2005)$.

23. C.J. Humphreys, Philos. Mag. 87, 1971 (2007).

24. P. Schlotter, R. Schmidt, J. Schneider, Appl. Phys. A 64, 417 (1997).

25. S. Neeraj, N. Kijima, A.K. Cheetham, Chem. Phys. Lett. 387, 2 (2004).

26. J.M. Phillips, M.E. Coltrin, M.H. Crawford, A.J. Fisher, M.R. Krames, R. Mueller-Mock, G.O. Mueller, Y. Ohno, L.E.S. Rohwer, J.A. Simmons, J.Y. Tsao, Laser Photonics Rev. 1, 307 (2007).

27. L.X. Zhao, E.J. Thrush, C.J. Humphreys, W.A. Phillips, J. Appl. Phys. (2008), In press.

28. L.A. Newman, M.T. Walker, R.V. Brown, T.W. Cronin, P.R. Robinson, Biochemistry 11, 12734 (2003).

29. N.K. van der Laak, R.A. Oliver, M.J. Kappers, C.J. Humphreys. Appl. Phys. Lett. 90, 121911 (2007).

30. D. Fuhrmann, T. Retzlaff, U. Rossow, H. Bremers, A. Hangleiter, Appl. Phys. Lett. 88, 1991108 (2006).

31. T. Akasaka, H. Gotoh, T. Saito, T. Makimoto, Appl. Phys. Lett. 85, 3089 (2004).

32. Y. Sun, Y. Cho, H. Kim, T.W. Kang, Appl. Phys. Lett. 87, 093115 (2005).

33. J. Harris, T. Someya, K. Hoshino, S. Kako, Y. Arakawa, Phys. Status Solidi A 180, 339 (2000).

34. A. Hangleiter, D. Huhrmann, M. Grewe, F. Hitzel, G. Klewer, S. Lahmann, C. Netzel, N. Riedel, U. Rossow, Phys. Status Solidi A 201, 2808 (2004).

35. D. Fuhrmann, U. Rossow, C. Netzel, H. Bremers, G. Ade, P. Hinze, A. Hanleiter, Phys. Status Solidi C 3, 1966 (2006).

36. M.A. Moram, Y. Zhang, M.J. Kappers, Z.H. Barber, C.J. Humphreys, Appl. Phys. Lett. 91, 152101 (2007).

37. Light Emitting Diodes for General Illumination. An OIDA Technology Roadmap (OIDA, Washington, DC, 2002).

38. Navigant Consulting Inc., Radcliffe Advisors for the U.S. Department of Energy, Multi-Year Program Plan FY08-FY13. Solid-State-Lighting Research and Development (March 2007; www.netl.doe.gov/ssl/PDFs/ SSLMPP2007-web.pdf) (accessed January 2008).

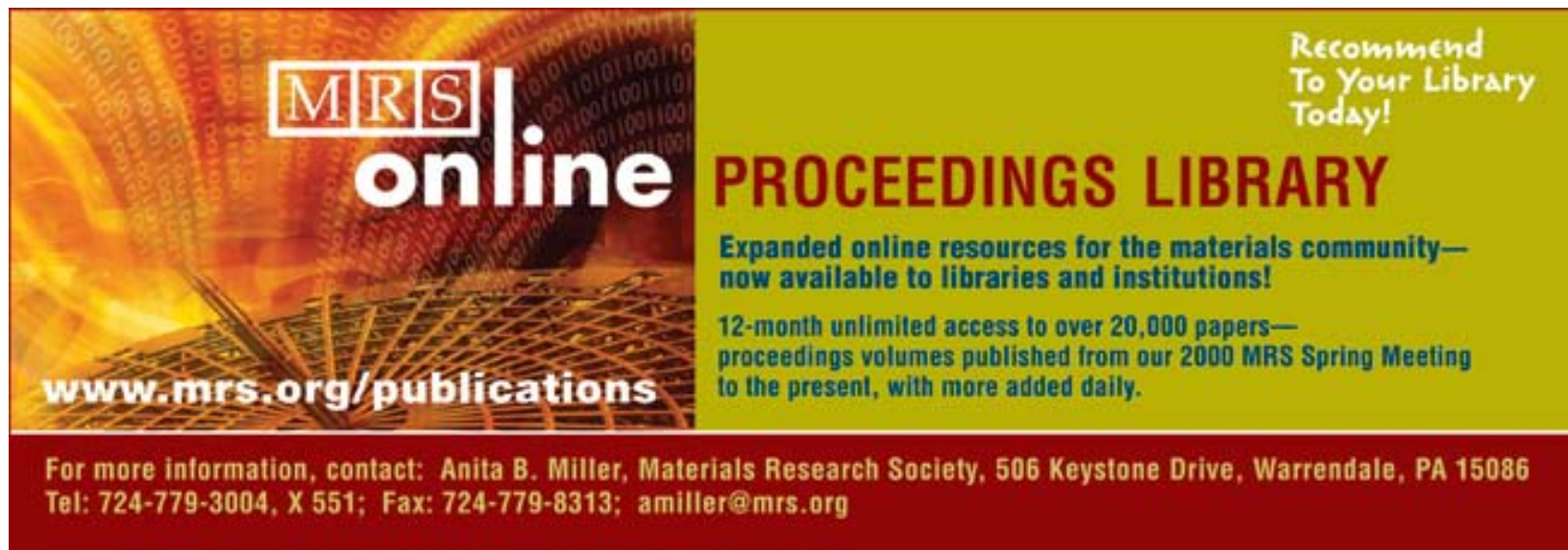




\section{Nature Publishing Group Covering the spectrum in the physical sciences}

Nature Publishing Group offers a range of journals in the physical sciences - from the broad scope of Nature to specific titles in physics, photonics, materials, nanotechnology, geosciences, chemical biology and, new for 2009, chemistry. Each journal carries a mix of research papers, reviews, news and views, and commentaries that keeps you up-to-date with the latest research in your area.

Visit www.nature.com to:

- register to receive table of content e-alerts

sign up for RSS feeds

- enter a personal subscription

recommend the journals to your library

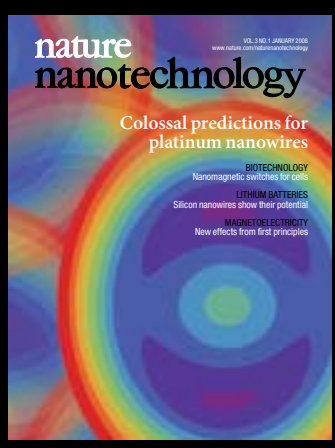

The finest research that brings science and technology toge
the nanoscale.

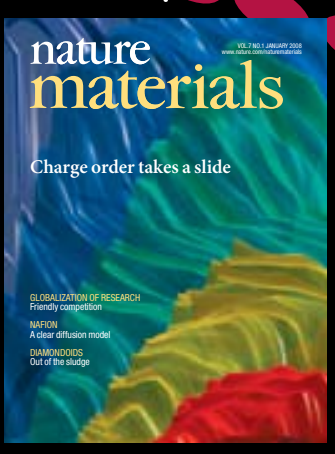

Impact factor: 19.194*

Cutting-edge research across the entire spectrum technology.

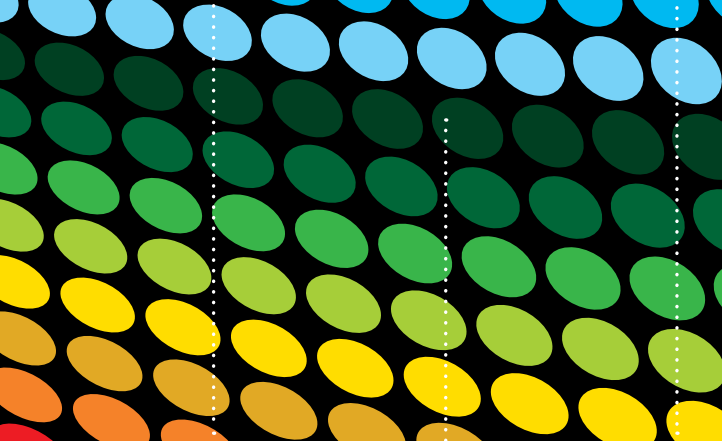

$$
\text { an }
$$

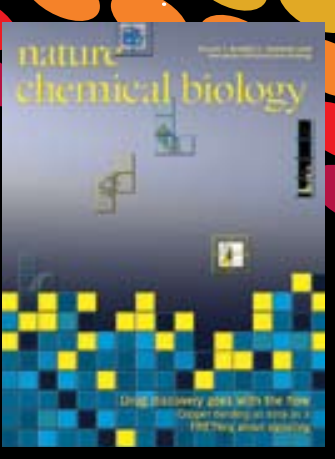

Impact factor: 12.409*

Innovative and indispensable research advances at
interface of chemistry and biology.

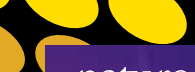

nature

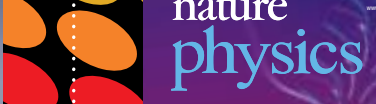
(

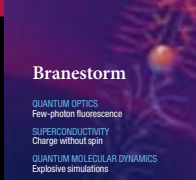

Impact factor: $12.040^{*}$

Top-tier research that covers physics: pure and applied.

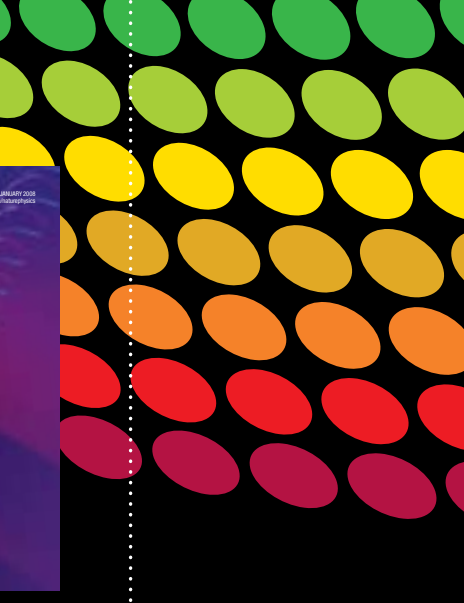

covers 